\title{
History II.O
}

\author{
Luka Orešković
}

\begin{abstract}
Science 2.0 is a concept of immense potential for the historical discipline. Throughout the world, researchers are undertaking different projects that attempt to harness the benefits of research efforts employing a wider community, be it fellow historians or the general public, and have reached different conclusions and results. Yet, most of these projects point to a clear direction in historical research of increasingly relying on the tremendous benefits that digital, and at times, Open Access to both scholarly work and primary sources has given them. While the idea of using Science 2.0 and crowd sourcing for historical research has produced a number of projects of great potential, Open Science and ideas of open publishing remain largely underutilized and avoided by the academic community of historians.
\end{abstract}

\section{Introduction: Issues and Opportunities of Open History and 2.0}

Science 2.0 is a concept of immense potential for the historical discipline. Throughout the world, researchers are undertaking different projects that attempt to harness the benefits of research efforts employing a wider community, be it fellow historians or the general public, and have reached different conclusions and results. Yet, most of these projects point to a clear direction in historical research of increasingly relying on the tremendous benefits that digital, and at times, Open Access to both scholarly work and primary sources has given them. While the idea of using Science 2.0 and crowd sourcing for historical research has produced a number of projects of great potential, Open Science and ideas of open publishing remain largely underutilized and avoided by the academic community of historians. Many issues arise between using Science 2.0 in historical research and becoming an

L. Orešković ( $₫)$

Harvard University, Cambridge, USA

e-mail: luka.oreskovic@gmail.com 
"Open Science" for history as an academic discipline, as opening academic history and research to Open Access, digital publication is both challenging and alarming for historians. It is challenging in terms of opening the field and competition in publishing historical work to a series of authors who might previously be disqualified due to lack of academic status such as scholarly success and track record as well as institutionally recognized intellectual credibility derived from a Ph.D. It is alarming in terms of economic constraints professional historians face today as institutions and fellow academics are unlikely to recognize scholarship published as Open Science, thus limiting career advancement possibilities in academia. While academic history increasingly comes to rely on open research platforms and Science 2.0 methods of historical research, it is likely that historical publishing, even though numerous new open publication platforms are developed, will remain largely limited to print or access-limiting journals and books.

\section{History 2.0: Developments, Directions and Conclusions}

A number of noteworthy projects either offering Open Access to historical sources or relying on crowd sourcing and online research contribution platforms that are open to a wider professional community or even the general public have come into being over the past years. While numerous platforms offer the general public Open Access to historical databases, projects that also involve contributors in the research effort are fewer. ${ }^{1}$ Still, several projects that pool research from a wide array of contributors, ranging from professional historians to the interested general public, have gained traction and achieved noteworthiness. Projects like University College London's Transcribe Bentham, ${ }^{2}$ National Geographic's Field Expedition: Mongolia, ${ }^{3}$ Founders and Survivors ${ }^{4}$ on Tasmanian convicts and University of Oxford's Ancient Lives and The project Woruldhord ${ }^{5}$ have achieved very successful collaboration among its members, and offer insight into successful practices for crowd sourcing historical research. ${ }^{6}$ Each of these projects in particular holds a valuable lesson on how crowd sourcing in historical research should be approached and raises both conceptual and practical questions about the nature of the practice.

\footnotetext{
${ }^{1}$ Diaspora: http://www.diaspora.illinois.edu/newsletter.html; Old Biley Online: http:// www.oldbaileyonline.org/

2 see Causer 2013

3 National Geographic: http://exploration.nationalgeographic.com/mongolia

${ }^{4}$ Founders and Survivors: http://foundersandsurvivors.org

5 Woruldhord: http://projects.oucs.ox.ac.uk/woruldhord/

${ }^{6}$ Ancient Lives: http://www.ancientlives.org
} 


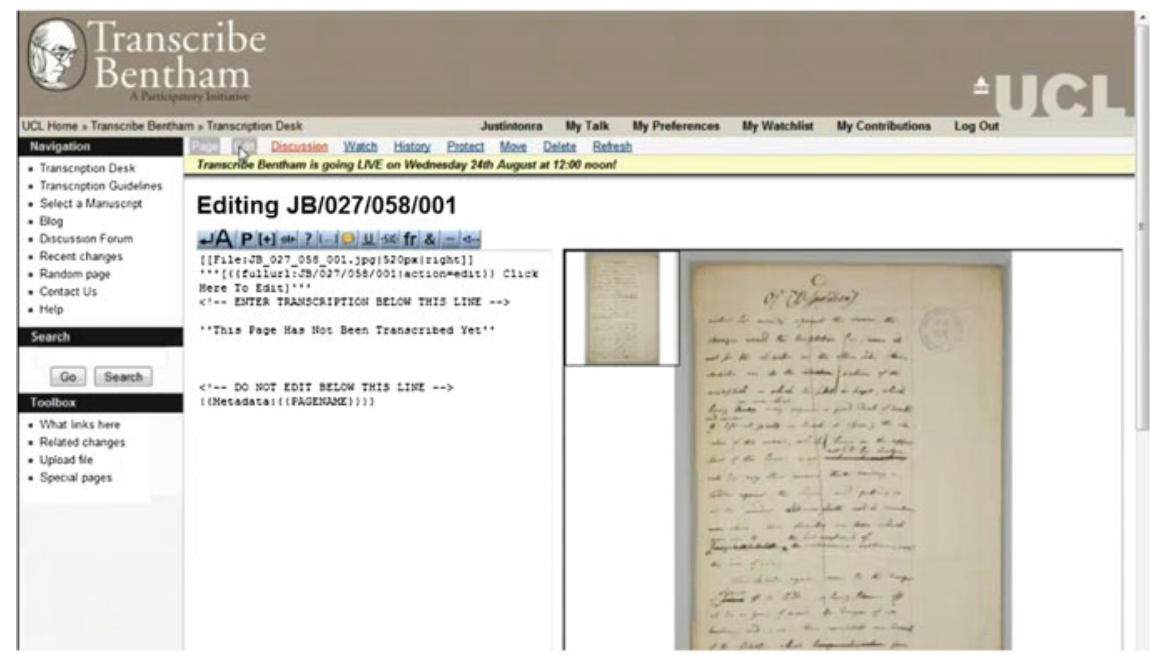

Fig. 1 Transcribe Bentham, University College London, Screenshot, February 26, 2013

\section{Types of Collaboration in Research Crowd Sourcing Projects}

Transcribing platforms-The University College London project Transcribe Bentham presents the most elementary of models for employing crowd sourcing in historical research. ${ }^{7}$ The project, as its name aptly describes, uses its members who join the platform from the wider public for transcribing original and unstudied manuscripts and documents written by the philosopher Jeremy Bentham with the aim of assembling an online database of all of Bentham's writing in unedited form. The elementary nature of this project is in the type of contribution it seeks from its members, using them as a free resource for manuscript transcription. Any contentlevel contribution is not possible in Transcribe Bentham yet its very nature and goal of completing an online database of Bentham's writings limits the level and type of members' contribution. The project attracted great attention and won the Prix Ars Electronica prize for Distinction in the Digital Communities (Fig. 1).

A very similar model is also employed by University of Oxford's Ancient Lives platform that allows users to transcribe the Oxyrhynchus Papyri through an online tool with specific symbols and scanned papyri. The tool allows anyone interested to contribute in the physical work of transcribing ancient manuscripts while the contributions are then analyzed, evaluated for accuracy by historians curating the project and and translated into English by professional translators. The historians, papyrologists and researchers providing curatorial oversight of contributions by

\footnotetext{
7 http://www.transcribe-bentham.da.ulcc.ac.uk/td/Transcribe_Bentham
} 


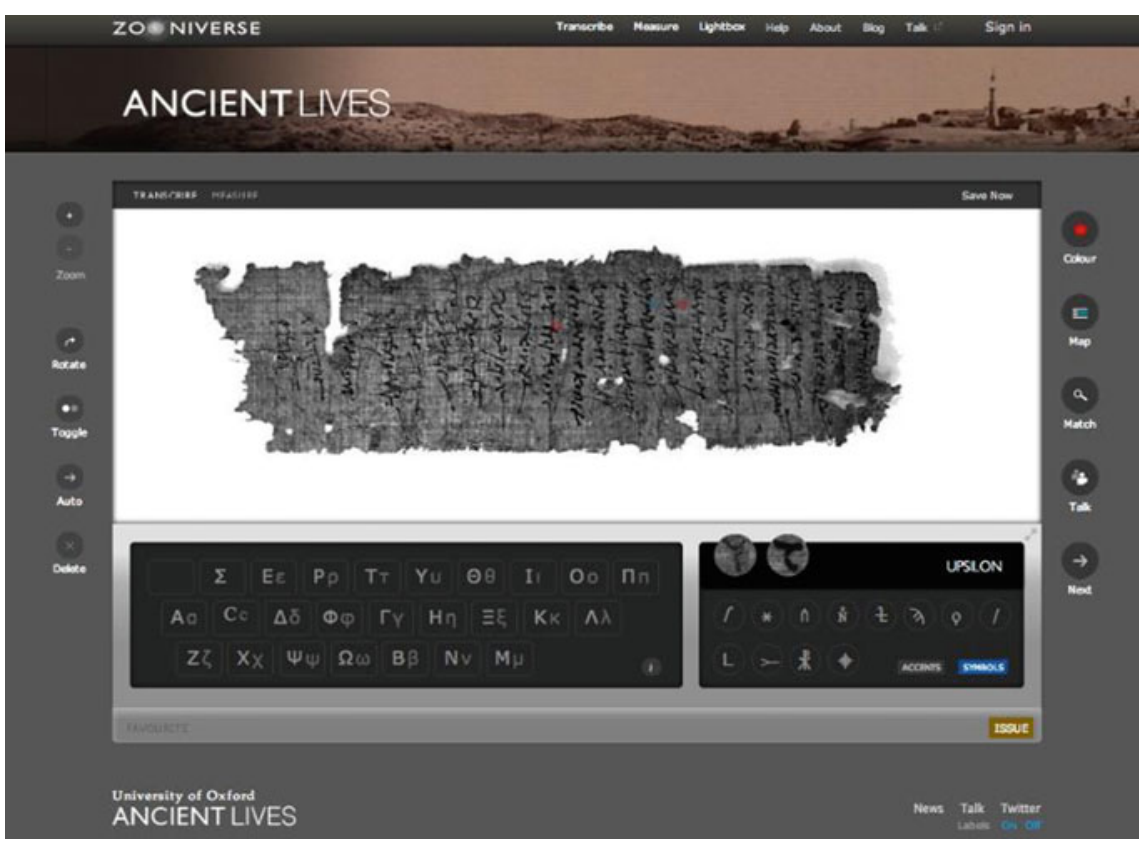

Fig. 2 Greek papyrus in the web interface for online transcription. Courtesy of Ancient Lives Project, Oxford

the participating public in the crowd sourcing project allows for academic accuracy and credibility, thus enabling more reliable usage of the material transcribed in the project (Fig. 2).

Projects that employ the crowd for transcribing and information pooling from the already existing resources, such as the Ancient Lives, Transcribe Bentham and others also implemented possibilities for crowd contributions such as forms for additional information on transcribed documents, indexing tools for transcribed documents or applications that provide a space for interaction and commentary among various contributors to the project about their work. While the first two additional contribution modes are of questionable applicability as they often require some degree of professional knowledge, the possibility of exchanging comments and experiences, coupled with the possibility of moderating such discussions for the purpose of establishing and sharing best transcription practices could be beneficial.

Content platforms-More demanding platform for participant collaboration in historical research was implemented by National Geographic's Field Expedition: Mongolia, The Founders and Survivors Project and University of Oxford's The project Woruldhord.

National Geographic's project might be the least beneficial one in terms of actual contributions to historical research, yet it represents an idea in the right 
direction that opens existing sources such as transcripts, documents or maps, for analysis by the general public, the results of which are then reviewed, curated and applied by professionals. The Field Expedition: Mongolia platform is based on an actual historical and archaeological project of search for Genghis Khan's tomb. The platform enables users, of whom there are an astounding 31,591 registered at the moment of writing this review, to review satellite imagery and tag it for objects and landmarks that researchers on the ground can then potentially utilize for their professional work. While the platform's aim is primarily to increase awareness of Mongolia's rich historical heritage than actually contributing to research on the ground, the idea of using crowd sourcing for more advanced research tasks that still demand substantial manpower and thus limit the number of professionals doing the work shows great promise.

Founders and Survivors project and University of Oxford's The project Woruldhord elevate collaboration of the participating public to a new level. Rather than relying on non-expert users for working or reviewing already existing sources, these two projects aim to build and assemble databases of historical primary sources submitted by users, thus relying on users for actual content building. Founders and Survivors isa study of the 73,000convicts transported to Tasmania between 1803and 1853, aiming toassemble a record systemof these convicts and buildupon this with data suchas health records,demographics andpersonal information. The project, in the words of its founders, aims to "combine professional expertise with the enthusiasm of volunteers." Some types of documents submitted by registered users in the project include conduct records, surgeons' journals, newspaper reports, births, deaths and marriages, parish records, family histories, memories and legends as well as formal sources like records from the convict system, trial and conviction documents and tickets of leave. Volunteers included genealogists and family historians, librarians, members of the wider public whose personal or family histories relate to the Tasmanian convicts and other researchers interested in the field. The submitted data is reviewed and organized by IT specialists and professional historians and published in the database (Fig. 3).

The applications of such a database are best exhibited in the number of research projects that arose from the Founders and Survivors project—-these include a study of Morbidity and mortality on the voyage to Australia, Crime and convicts in Tasmania, 1853-1900, Fertility decline in late C19 Tasmania, Prostitution and female convicts and Tracing convicts' descendants who served in WWI. The success of the projectcan largely be attributedto relying on a largenumber of public users forresearch while navigatingand moderating theirresearch through bothprepopulated forms thatlimit the type of data andinformation users can submit as well asprofessional curation byhistorians and otherspecialists (Fig. 4).

A very similar model is used by University of Oxford's The project Woruldhord that collects a database of photographs, documents and presentations relating to Anglo-Saxon centered English History and Old English literature and language. The materials in The project Woruldhord were collected from both members of the public, free to submit any documents related to the period and field of Woruldhord as well as museums, libraries, academics and scientific societies and resulted in a 


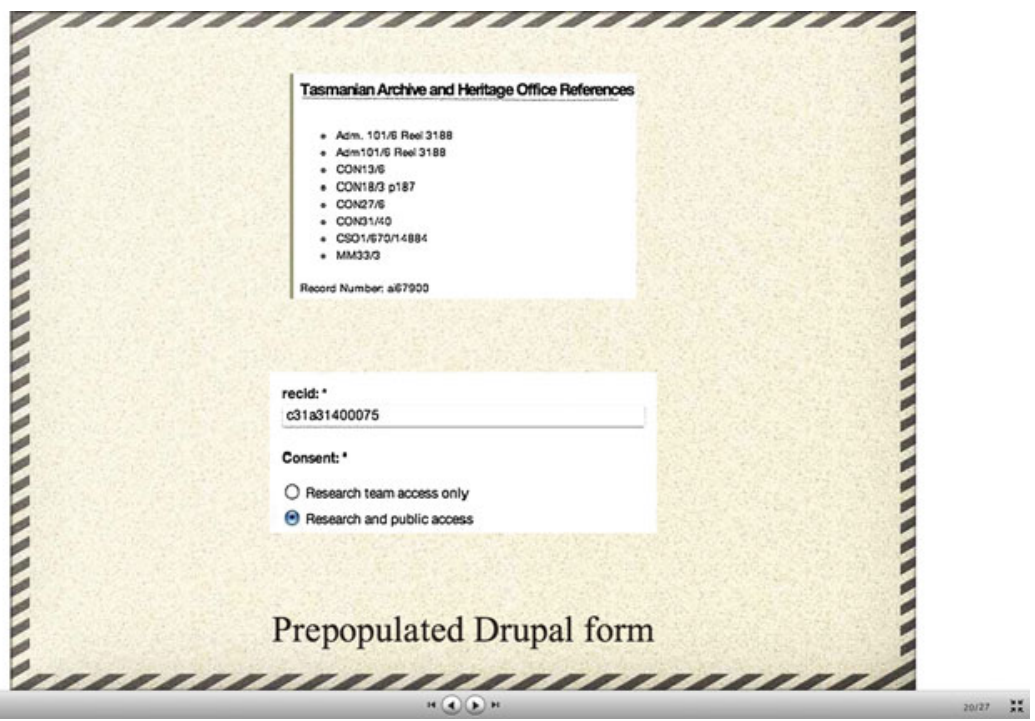

Fig. 3 Prepopulated Form, Crowdsourced project structure, instructional process and workflow designed by Professor Janet McCalman, Centre for Health \& Society, University of Melbourne, with technical assistance from Sandra Silcot and Claudine Chionh. Funded by the Australian Research Council

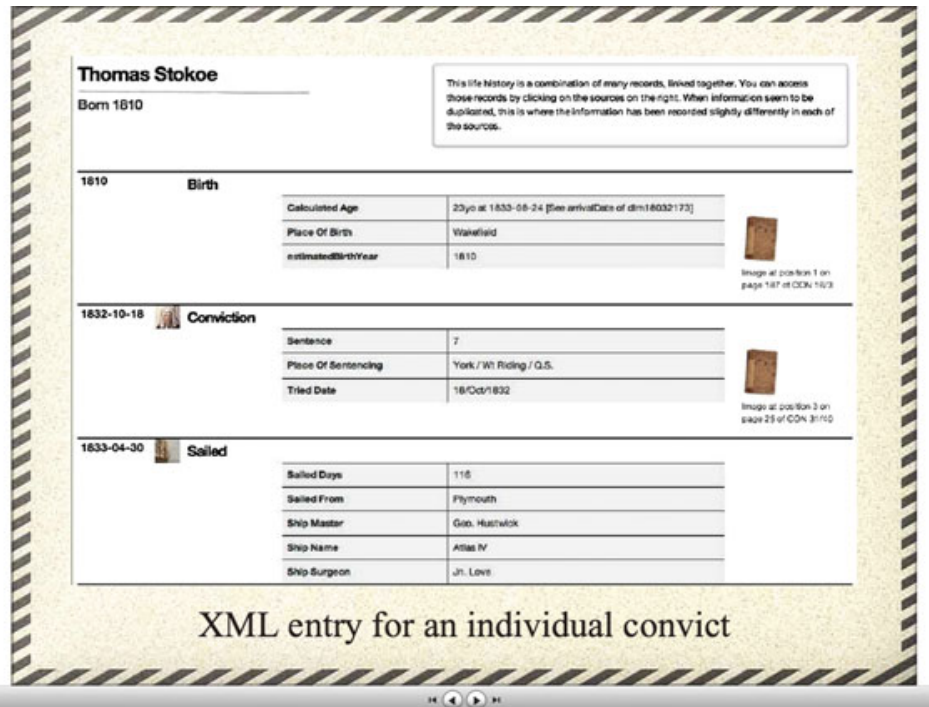

Fig. 4 Sample Entry for an Individual Convict, Crowd sourced project structure, instructional process and workflow designed by Professor Janet McCalman, Centre for Health \& Society, University of Melbourne, with technical assistance from Sandra Silcot and Claudine Chionh. Funded by the Australian Research Council 


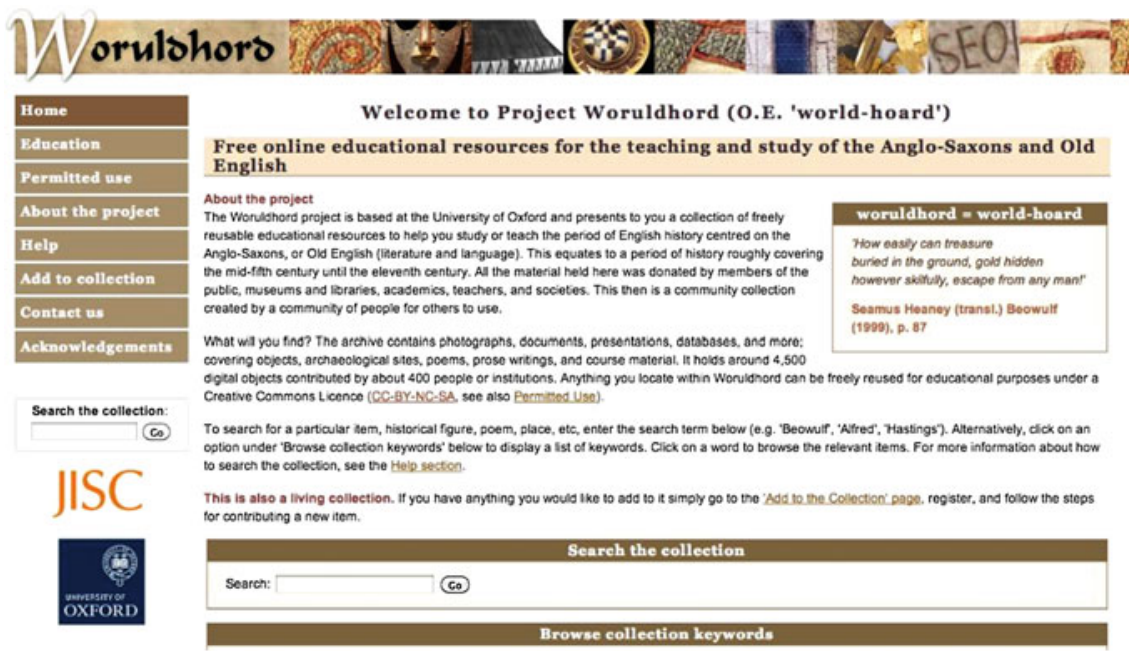

Fig. 5 Project Woruldhord, University of Oxford, February 27, 2013

collection of approximately 4,500 various digital objects. Woruldhord's own description appropriately terms the project a community collection open to access of everyone interested in the field (Fig. 5).

Projects like Founders and Survivors and Project Woruldhord exemplify the frontier of crowd sourcing practices for historical research that employ the general public for content contribution and aggregate databases of primary sources that are broader in scope than many projects have achieved in spite of having a larger professional staff and more funding.

\section{Conceptual Questions and Challenges}

Edward L. Ayers, currently the President of University of Richmond, argued in 1999 in his seminal essay on "The Pasts and Futures of Digital History" that history as an academic discipline underwent "democratization" while meaningful "democratization of the audience" was lacking at that time (Ayers 1999). His hope was that the "digital world" might be able to, once again, spur innovation in academic history and it is possible that this time has arrived. History as a 2.0 Scienceand eventually, an OpenScience, has the potentialto involve professional historians globally moreclosely than ever before,creating platforms for collaborations across disciplines of academichistory. Although historians are increasingly relying on collaborative and crowd sourcing platforms for their research, the methods also give rise to questions of the role of historians in the research process. Shawn Graham, Assistant Professor of Digital Humanities in the Department of History at Carleton University, together with two students at Carlton, wrote a Case 
Study on a crowd sourcing project they administered (Graham et al. 2012). In this case, they raise questions of what the role of historians in projects relying on crowd sourcing for historical research is as well as claims over authorship of the work of history that results from crowd sourcing research. Namely, is the research produced this way primarily historian's or the crowd's? In answering this and similar questions, it is important to keep in mind that all the aforementioned projects were curated and led by professional historians. The established processes of source review and criticism in history demand professional expertise and thus, any crowd research efforts or community contributed content (CCC) projects still closely rely on guidance and review processes by professional historians (cf. Howell and Prevenier 2001).

\section{Conclusions}

Crowd sourcing and Science 2.0 in academic history holds the potential of unparalleled access to research resources for historians focusing on a range of fields, from "big history" to "microhistory" as well as everything in between. Access to the plethora of perspectives, personal data and documents from individual repositories of the past, family histories and communal archives is already attracting numerous historians, with future trends set to continue in this direction. Yet there is still a big gap between utilizing Science 2.0 (online resources) for research and making history an Open Science in terms of publishing practices. Economic constraints such as a shrinking market for academic appointments in history are among the most often mentioned reasons for historians' shying away from open publishing as academic institutions that recognize such publications are rare. Hesitance to recognize "Open Science" publishing as reference for academic track record is understandable, and the hesitance is not only on the part of academic institutions. The Open Source knowledge and publishing processes already have considerable drafting and review procedures in place, but there is space for improvement. While the transparency of review processes that are noticeable in the "Open Science" are laudable, the critical review of submissions can still be improved and in accordance with the principles of Open Science, it will likely keep improving (forever?). As Open Science publishing practices reach the level of high-quality peer review and editorial processes that traditional academic publications exhibit, it will be upon academic institutions to begin recognizing open source knowledge and publications as contributing to the scholarly success and track record of its faculty. The widely covered "Memorandum on Journal Pricing" published by Harvard Library's Faculty Advisory Council in April of 2012 calls on all Harvard Faculty Members in all Schools, Faculties, and Units to, among other things, make sure their papers are accessible by submitting them to Harvard's DASH Open-Access repository as well as consider "submitting articles to Open-Access journals, or to ones that have reasonable, sustainable subscription costs; move prestige to Open Access". The Council also asked scientists to sway 
journals that restrict access to their content to become more open. ${ }^{8}$ If impossible to make these journals Open Access, the members of Harvard Library's Faculty Advisory Council recommend to their Harvard peers to consider resigning such journals' advisory boards. While calls from Harvard's Library have been welcomed in numerous publications worldwide, the memorandum also raises questions on the issue of peer and institutional recognition of open source publishing as relevant to scholarly track record. Many headlines cited "Memorandum on Journal Pricing" as ultimate proof that current publishing pricing practices are economically impossible since Harvard, the wealthiest of academic institutions globally, could not afford them. As Open Science platforms continue to grow in prominence, Harvard should take the first step in encouraging research published as Open Science to be weighted more equally compared with more traditional publishing platforms.

Open Access This chapter is distributed under the terms of the Creative Commons Attribution Noncommercial License, which permits any noncommercial use, distribution, and reproduction in any medium, provided the original author(s) and source are credited.

\section{References}

Ayers, E.L. (1999). The pasts and futures of digital history. Available at: http:// www.vcdh.virginia.edu/PastsFutures.html.

Causer, T. (2013). Welcome to transcribe bentham. Transcribe Bentham. Available at: http:// blogs.ucl.ac.uk/transcribe-bentham/.

Graham, S., Massie, G., \& Feurherm, N. (2012). The heritage crowd project: A case study in crowd sourcing public history (Spring 2012 version). Available at: http:// writinghistory.trincoll.edu/.

Howell, M. C., \& Prevenier, W. (2001). From reliable sources: an introduction to historical methods. Ithaca, New York: Cornell University Press.

${ }^{8}$ Faculty Advisory Council Memorandum on Journal Pricing: http://isites.harvard.edu/icb 